\title{
REVIEW OF MEDICAL DESCRIPTION OF CERVICAL CYTOLOGY
}

\author{
Umbreen Naz ${ }^{1}$, Farhan Sarwar², Muhammad Adnan Sarwar ${ }^{3}$, Muhammad Mudassar Ashraf ${ }^{4}$, \\ Muhammad Shoaib Zafar ${ }^{5}$, Muhammad Waqas Khadam ${ }^{6}$ \\ ${ }^{1}$ Departments of Obstetrics and Gynecology, ${ }^{2}$ Orthopedics, ${ }^{3}$ Medicine, Faisalabad Medical University, \\ Faisalabad, ${ }^{4}$ Department of Eastern Medicine, Directorate of Medical Sciences, Government College \\ University, Faisalabad, ${ }^{5}$ Department of Pharmacology, University of Health Sciences, Lahore, ${ }^{6}$ Institute of \\ Pharmacy, Physiology and Pharmacology, University of Agriculture, Faisalabad, Pakistan
}

\begin{abstract}
Cervical cancer is a malignant neoplasm of the cervical area or cervix which may present with the vaginal bleeding but symptoms may be absent until the cancer gets in advanced stage. Dysplasia seen on cervical biopsy uses the term cervical intraepithelial neoplasia $(\mathrm{CIN})$ and is grouped into mild $(\mathrm{CIN}-1)$, moderate $(\mathrm{CIN}-2)$ and severe $(\mathrm{CIN}$ 3). The severity of $\mathrm{CIN}$ depends upon cellular disorganization, cellular immaturity, increased mitotic activity and nuclear abnormalities. The nuclear atypia, extent of mitotic activity and immature cellular proliferations identifies the degree of dysplasia. Thus, epithelial thickness which shows differentiation is the useful feature in decision about severity of CIN. Treatment of this cancer may be ablative and/ or excision. Cryotherapy is a reasonable treatment of $\mathrm{CIN}-1$ and $\mathrm{CIN}-2$ but not of $\mathrm{CIN}-3$ which is severe cervical carcinoma. Burning the TZ-transformation zone (Electro diathermy) destroys the tissue more effectively than that of cryotherapy but it usually requires general anesthesia, however laser cold coagulations technique requires local anesthesia usually. Laser TZ Excision compromises the fertility. Knife cone biopsy is used as a preferred treatment for removal of abnormal cervical cells. Now the cone biopsy is generally performed using the laser surgery. Early diagnosis of cervical cancer is very necessary for better control and treatment of it. For early phases of cervical carcinoma, the cryotherapy is very reasonable, however in case of late stage of the disease laser methods are used alone or on combination. Therapy will be termed successful if cytology remains negative after at least six months of its treatment.
\end{abstract}

KEY WORDS: Cervix; Cervical; Cervical Biopsy; Cervical Cancer; Vaginal Bleeding; CIN, Cervical Intraepithelial Neoplasia; Cellular Proliferations; Differentiation; Cryotherapy.

This article may be cited as: Naz U, Sarwar F, Sarwar MA, Ashraf MM, Zafar MS, Khadam MW. Review of medical description of cervical cytology [review article]. Gomal J Med Sci 2019 Oct-Dec; 17 (4):150-54. https:// doi.org/10.46903/gjms/17.04.1998

\section{INTRODUCTION}

\section{Anatomy of the Cervix}

Uterus, a hollow muscular chamber, is a central organ of reproductive system in women and gives protection to developing fetus during pregnancy. Cervix lies below uterus which projects obliquely into vagina and can be divided into the vaginal portion

\section{Corresponding Author:}

Dr. Muhammad Mudassar Ashraf

Assistant Professor, Department of Eastern Medicine

Directorate of Medical Sciences

Government College University, Faisalabad

Faisalabad, Pakistan

E-mail: mudassar_pharmacist@yahoo.com

Date Submitted: 23-03-2019

Date Revised: $\quad 09-06-2019$

Date Accepted: $\quad 30-07-2019$ and supravaginal portion. Cervix is narrower than that of the uterus body. Long axis of the cervix is rarely same due to anteflexion or retroflexion. Cellular connective tissue, the parametrium, is present on anterior and lateral to supravaginal portion of cervix. It is posteriorly covered by peritoneum of the Pouch of Douglas (POD). The ureter runs one $\mathrm{cm}$ lateral to the supravaginal cervix. ${ }^{1,2}$

\section{Vaginal Portion}

Vaginal portion projects into the vagina and forms fornices. The upper part of the cervix mostly consists of involuntary muscle, whereas its lower part consists mainly of the fibrous connective tissues. The mucosa of endocervix form arborvitae. It has deep glandular cells which secrete a clear and alkaline mucus which is the main component of vaginal discharge. ${ }^{3}$ Endocervix is composed of columnar epithelium. Ectocervix has stratified squamous 
epithelium present around the region of the external os. ${ }^{4}$ This squamocolumnar junction (SCJ) is termed as transformation zone (TZ) which is an area of rapid cellular division and about $90 \%$ of the cervical carcinoma_arises in this area.

\section{Squamocolumnar Junction/TZ}

It is an area of the rapid cellular turnover and squamous metaplasia. It is the main site of oncogenic transformations. In young ladies of child bearing age, the SC Junction is readily visible on the ectocervix. As cervical epithelium gets matured, the Squamocolumnar Junction (SCJ) is receded within the endocervical canal which makes the SCJ visualization and adequate sampling difficult. The $\mathrm{SC}$ is a dynamic point and may be changed in response to hormonal stimulation, puberty, pregnancy and menopause etc. At menarche time, estrogen causes the vaginal epithelium to get filled with the glycogen. Lactobacilli act on the glycogen and produces lactic acid which in turn decreases the $\mathrm{pH}$ and stimulates the columnar cells to undergo metaplasia. ${ }^{5}$ Metaplasia advances from the original SCJ inwards, toward the external OS and over the columnar villi. This process establishes an area called as transformation zone. It extends from original SCJ to active SCJ physiologically. ${ }^{4}$

\section{DISCUSSION}

\section{Cervical (Cx.) Dysplasia}

Dysplasia means an "abnormal maturation", consequently the proliferating metaplasia without any mitotic activity should never be called dysplasia. Squamous metaplasia also should not be diagnosed as a dysplasia or as CIN as it does not progress to an invasive cancer.

A precancerous change in the squamous epithelium of the transformation zone of the cervix is called as cervical dysplasia. It is also known as cervical intraepithelial neoplasia $(\mathrm{CIN})$ or as squamous intraepithelial lesion (SIL). Cervical dysplasia, when observed under the microscope, is an abnormal appearance of the cells on the cervical surface. Although this is not a cancer but it is considered as a precancerous condition. 6

\section{Cervical (Cx.) Cancer}

The malignant neoplasm of the cervix or cervical area is called cervical cancer which may present with vaginal bleeding but its symptoms may be absent until the cancer is in advanced stage. 6

The knowledge of historical background of cervical cytology will be helpful in planning, implementing and evaluating a program for prevention of cervical cancer in low resources settings.7

\section{PATHOGENESIS}

Certain factors are involved in the development of cervical neoplasm which has been identified from a series of molecular, clinical, epidemiological and pathological studies. Their risks factors include being at an early age during her first intercourse, having multiple sexual partners or having one male partner with his multiple sexual partners. Other potential risk factors include use of oral contraceptives, smoking, multi-parity, family history, genital infections and lack of circumcision is opposite sexual partner. ${ }^{2}$

Cervical carcinoma was mostly found in poor patients or persons with low income. Parity of the patients also plays a major role in prevalence of cervical carcinoma. ${ }^{8}$

\section{Cervical Oncogenesis}

Human papilloma virus (HPV) infection is the essential pre-requisite for the development of cervical malignamey. ${ }^{7}$ Estimated prevalence of HPV in cancer of cervix is 99.7 percent. ${ }^{8}$ Papilloma virus has linkage to cancer in general and cervical cancer in particular. ${ }^{9}$

Co-carcinogens, nutrition, immune status of the individual and many other factors influence whether the HPV infection remains subclinical, turns into precancerous or eventually progresses to cancer. . $^{9,11}$ Low level of RBC folates enhances the effect of other risk factors for cervical dysplasia and in particularly for HPV infection. ${ }^{12}$ Oral contraceptives have been reported to cause megaloblastic changes in cervical epithelial cells, ${ }^{2}$ fall in blood folate levels ${ }^{12}$ and increase in incidences of cervical intra epithelial neoplasia. ${ }^{1}$

The exterior part of the cervix is continuous with vagina and is lined with flat or squamous cells; whereas the cervical interior surface is lined with tall or columnar cells. At the junction point of these two cell types (squamo-columnar junction) abnormal cellular growth or cervical dysplasia may occur. ${ }^{1,2}$

Concept about the pre-invasive disease of cervix was introduced in 1947 when it was recognized that changes in cervical epithelium could be identified. ${ }^{13,14}$

The World Health Organization classifies cervical dysplasia as mild (CIN-1), moderate (CIN-2) and severe (CIN-3) as well as a separate category for carcinoma in situ (CIS). The CIN severity is dependent upon cellular immaturity, cellular disorganization, nuclear abnormalities and increased mitotic activity. The extent of mitotic activity, nuclear atypia and immature cellular proliferations identifies the degree of dysplasia. So, the proportion of the thickness of epithelium showing differentiation is useful feature in deciding the severity of CIN.

1. CIN-1: Immature cells are present only in lower $1 / 3^{\text {rd }}$.

2. CIN-2: When middle one third of epithelium is also involved.

3. CIN-3: When upper one third (whole epithelium is involved but basement membrane is intact) or when full thickness of cervix has abnormal cells. ${ }^{1,2}$ 
Microscopically main types are as follows. ${ }^{15}$

1. Squamous cell carcinoma (75\%)
a. Micro invasive
b. Invasive

2. Adeno carcinoma $10 \%$

3. Adeno squamous carcinoma $10 \%$

4. Neuro endocrine (Small cell) carcinoma $5 \%$

\section{TREATMENT}

There are two categories of its treatment. ${ }^{16,20}$

A. Ablative; including cryotherapy, radical electro diathermy, cold coagulation and carbon dioxide laser

B. Excisional; including (LETZ/LEEP), laser TZ Excision, knife cone biopsy, laser cone biopsy, loop cone biopsy and hysterectomy

\section{A. ABLATIVE TECHNIQUES ${ }^{4}$}

Ablative therapy is appropriate in case of following conditions.

a. No evidence of micro invasive or invasive cancer on cytology, endocervical curettage, colposcopy or biopsy.

b. The lesion is located on the ectocervix and can be seen entirely.

c. No involvement of the endocervix is found as determined by colposcopy and endocervical curettage.

\section{Cryotherapy (Freezing the tissue)}

It is easy to use and cheap with low morbidity. ${ }^{10}$ It destroys the surface epithelium by crystallizing the intracellular water, resulting is destruction of the cells up to $4 \mathrm{~mm}$ deep. Temperature needed must be -20 to $-30^{\circ} \mathrm{C}$. Nitrous oxide and $\mathrm{CO}_{2}$ produce temperature below this range and, therefore, are most commonly used for this procedure. It should be used as a double Freez-thaw-freez technique. ${ }^{17}$

Cure rates are related to the grade of lesion and sizes of the session also. CIN-3 has a greater failure rate. Success rates for treating CIN-3 vary between 77-93\%. ${ }^{9}$ Presence of positive endocervical curettage can significantly reduce the cure rate, so failure rate is $27 \%$ as compared with $9 \%$ in those who did not have such involvement. ${ }^{18}$

Cryotherapy is a reasonable option for treating low grade disease i.e. CIN-1 but not of high grade disease i.e. CIN-3. It may be suitable in resource poor situation. Whereas, other ablative and excisional methods achieve cure rates of about $90-98 \%{ }^{10}$

\section{Electro diathermy (burning the TZ)}

It destroys the tissue more effectively than cryotherapy, but requires local, regional or general anesthesia, usually requires $\mathrm{GA}$. It is possible to destroy up to 1 $\mathrm{cm}$ depth using combination of the needle and the ball electrodes. ${ }^{17}$

3. Cold Coagulations (destroying the TZ by applying a probe heated to $100-120^{\circ} \mathrm{C}$ )

Cold coagulation was term coined by Kurt Semm in 1996 and does not require analgesia. Heat is applied to tissues using a Teflon-coated thermo-sound at $100 \mathrm{C}^{\circ}$. After treatment at $100 \mathrm{C}^{\circ}$ for $30 \mathrm{sec}$, the destruction depth is approximately $2.5-4 \mathrm{~mm}$ and exceeds up to $4 \mathrm{~mm}$ after treatment at $120 \mathrm{C}^{\circ} .{ }^{3,18} \mathrm{It}$ requires usually local anaesthesia. ${ }^{10}$

\section{Vaporization (vaporizing the tissue)}

Laser vaporization therapy may be chosen for patients in whom invasive cancer is ruled out, entire lesion can be seen and endo cervical curettage is negative. It requires local anaesthesia. ${ }^{10}$

Laser vaporization is applicable in the following situations particularly:

a. Large lesion where cryoprobe cannot cover adequately.

b. Irregular cervix with a deep clefs and fish mouth appearance.

c. Extension of disease to vagina or satellite lesions on vagina (as there is no gland crypts in the vaginal epithelium, destruction to depth of 2-3 $\mathrm{mm}$ is adequate). ${ }^{17}$

d. Lesion with extensive glandular involvement in which treatment must reach beyond the deepest gland cleft.

Laser vaporization has advantage of having ability of exactly controlling the depth and width of destruction by direct vision through the colposcope and minimal thermal damage to adjacent tissue. Wright and Reopelle have shown that destruction up to depth of $3.8 \mathrm{~m}$ will ablate all involved glands in $99.7 \%$ of cases. Tissue should nevertheless be ablated up to $7 \mathrm{~mm}$ depth (deepest endocervical gland). With laser vaporization therapy there is rapid post-treatment healing phase (approximately 3-4 weeks) and good haemostasis. ${ }^{19}$

\section{Laser Technique \& Tissue Interaction}

Laser therapy should be performed during the first week following LMP, and in non-pregnant females. It may be performed on out patients with or without anesthesia when the laser beam contacts tissue, its energy is absorbed by the water in the cells, causing it to boil instantly, the cells explode into a puff of vapor (therefore, the term laser vaporization). ${ }^{4}$

\section{B. EXCISIONAL METHODS}

\section{Loop TZ Excision (LLETZ/NETZ)/ Laser TZ Ex- cision}

It is a valuable tool for treatment and diagnosis of CIN. Both laser and diathermy loops have been used for this purpose. The entire transformation is removed along with varying amount of the cervical 
canal, thus potentially compromises the fertility. ${ }^{20}$ The cervix is evaluated colposcopically to delineate the lesion and determine the endocervical canal involvement; local anesthesia is given at the line of excision. The selected lop is based on the TZ, to excise the tissue in one piece. Hemorrhage and cervical stenosis can occur but at acceptable low rates. Advantages are, treatment time is shorter, cone sample is better than with laser, the ability to diagnose un-suspected invasive disease and there is less handling of the tissue.

Following are contra indications to loop procedure. ${ }^{4}$

a. Patients' anxiety

b. Sensitive to local anesthesia

c. Extremely large lesions

d. Vaginal extension and obvious clinical carcinoma

2. Cone Biopsy/ Cervical Conization (Knife cone, Loop cone, Laser cone)

Conization of cervix plays an important role in management of $\mathrm{CIN}$, has both diagnostic and therapeutic advantage. Conization is the treatment of choice is following conditions.

a. Limit of the lesion is not visualized with colposcope.

b. The SCJ is not seen at colposcope.

c. Endocervical curettage shows CIN-2 or CIN-3.

d. There is no correlation between cytology, colposcopy or biopsy results.

e. Micro invasion is suspected based upon biopsy, cytology or colposcopy results.

Knife cone biopsy is the preferred treatment for removing abnormal cells present in the cervix. Now, the cone biopsy is generally performed using laser surgery. The risks are bleeding, infection, incompetent cervix and impairment of fertility. ${ }^{4,17,21,22}$

\section{Hysterectomy}

There are few situations when hysterectomy remains an appropriate and valid method for treatment of $\mathrm{CIN}{ }^{4}$

a. Micro invasion

b. Cervical intra epithelial neoplasia at the limits of conization specimen.

c. Other associated gynecological problems requiring for hysterectomy such as prolapse, fibroids, endometriosis and PID.

d. Poor compliance with follow up.

\section{FOLLOW UP AND SUCCESS OF TREATMENT}

After treatment, cytological screening is recommended at three months interval for first two years, six monthly thereafter for three years and then yearly for next five years. Total follow-up period will be ten years. ${ }^{3}$ Success of treatment of cytology of cervix is usually defined as negative cytology for six months following intervention. ${ }^{11}$

\section{CONCLUSION}

Pap-smear testing of patients on regular basis is very crucial for early diagnosis of cervical cancer. For early phases of cervical carcinoma like CIN-1 and CIN-2, the cryotherapy is very reasonable. However, in case of late stage of the disease (CIN-3), laser methods are used alone or in combination. The best combinational therapy is the cone biopsy along with the laser technique. Treatment of cervical cytology is considered successful if cytology will remain negative for at least after six months after therapy.

\section{REFERENCES}

1. Yarbo CH, Debra W, Barbara HG. Cancer Nursing: Principles and Practices. 7th ed. Jones and Bartlett Publishers: Sudbury; 2011.

2. Boardman $\mathrm{CH}$, Warner $\mathrm{KH}$. Cervical Cancer. Medscape 2016. [accessed 2019 March 12]. Available at: https://emedicine.medscape.com/ article/253513-overview.

3. Monga A, Dobbs S. Premalignant and malignant disease of the cervix. In: Gynecology by ten teachers. Ed: Kenny LC and Myers JE. 19th ed. London: Arnold; 2011.p.125-33.

4. Hatch KD, Berek JS. Intraepithelial disease of cervix, vagina and value. In: Berek JS, editor. Novak's Gynecology. 13th ed. London: Williams \& Wilkins; 2002. p. 471-505.

5. Rivlin ME, Martin RW. Carcinoma of cervix. In: Manual of clinical problems in obstetrics and gynecology. 5th ed. Philadelphia: Lippincott William \& Wilkins; 2000. p. 429-33.

6. Storck S. Cervical dysplasia. StatPearls Publishing LLC. [accessed 2019 Jan 12] Available from: adam.about.net/encyclopedia/cervical-dysplasia-series.html

7. Rashid A, Umbreen N, Adnan S, Muhammad MA, Zahid M, Shaukat HM, et al. Historical perspective of cervical cytology: A review. J Uni Med Dent Col 2017; 8(4):1-6.

8. Naz U, Abid R, Farhan S, Sarwat A, Muhammad MA, Ahsan S. Association of age groups, parity and socioeconomic status with abnormal pap-smear. J Soc Obstet Gynaecol Pak 2017; 7(4):191-5.

9. Burd EM. Human Papillomavirus and cervical cancer. Clin Microbiol Rev 2003; 16(1): 1-17. https:// doi.org/10.1128/CMR.16.1.1-17.2003

10. Downey G. Preinvasive disease. In: Luesley DM, Baker PN, editors. An evidence-based text for MRCOG. 2nd ed. London: Arnold; 2010.p. 789-96.

11. Boyd JA, Hamilton TC, Berchuck A. Oncogenes and tumour suppressor genes. In: Hoskins WJ, Perez CA, Young RC, editors. Principles and practice of gynaecological oncology. 3rd ed. Philadelphia: Williams \& Wilkins; 2000.p.103-28.

12. Piyathilake CJ, Macaluso M, Brill I, Heimburger DC, Partridge EE. Lower red blood cell folate 
enhances the HPV-16-associated risk of cervical intraepithelial neoplasia. Nutrition 2007; 23(3): 203-10. https://doi.org/10.1016/j.nut.2006.12.002

13. Dim CC. Towards improving cervical cancer screening in Nigeria: A review of the basics of cervical neoplasm and cytology $2012 ; 15(3)$ : 247 52. https://doi.org/10.4103/1119-3077.100615

14. Pund ER, Neiburgs $H$, Nettles JB. Preinvasive carcinoma of the cervix uteri: Seven cases in which it was detected by examination of routine endocervical smears. Arch Pathol Lab Med 1947; 44: 571-7.

15. Souther P. Premalignant disease of lower genital tract. In: Shaw RW, Souther WP, Stanton SL, editors. Gynecology. 2nd ed. London: Churchill Livingstone; 1997.p. 521-40.

16. Nausheen A, Karim SA. The screening for cervical cancer by Pap smear in hospital based population. Annals ASHKMDC 2004; 9: 544-7.

17. Shafi MI. Premalignant and malignant disease of cervix. In: Edmonds K, editor. Dewhurst's textbook of obstetrics \& gynecology. 7th ed. Oxford: Blackwell; 2007.p. 614-23.

18. Solomon D, Schiffman M, Taron R. Comparison of three management strategies for the patients with atypical squamous cells of undetermined significance: baseline results from a randomized trial. J Natl Cancer Inst 2004; 93: 293-318. https:// doi.org/10.1093/jnci/93.4.293

19. Bacon JL. Carbon dioxide laser surgery in gynecology. Medscape. [updated 2018 Sep 20, accessed 2019 Jan 12]. Available at: https://emedicine.medscape.com/article/272382-overview

20. Saha M, Iffat A, Sabera K, Suvash CR, Tapan KS. Loop Electrosurgical excision procedure of the transformation zone: an outpatient procedure. Bang J Obs Gyn 2012; 27(1): 5-8. https://doi. org/10.3329/bjog.v27i1.29906

21. Manjit SB, Rishu G, Anil KS, Manjit KM. Detection of abnormal cervical cytology in Papanicolaou smears. J Cytol 2012; 29(1): 45-7. https://doi. org/10.4103/0970-9371.93222

22. Mulazim HB, Kanwal S, Samina Q, Muhammad MM, Shahida N, Samina N. Clinicopathological importance of Papanicolaou smears for the diagnosis of premalignant and malignant lesions of the cervix. J Cytol 2012; 29(1): 20-5. https://doi. org/10.4103/0970-9371.93213

CONFLICT OF INTEREST
Authors declare no conflict of interest.
GRANT SUPPORT AND FINANCIAL DISCLOSURE
None declared.

\section{AUTHORS' CONTRIBUTION}

The following authors have made substantial contributions to the manuscript as under:

Conception or Design:

UN, FS, MAS

Acquisition, Analysis or Interpretation of Data:

UN, FS, MAS, MMA, MSZ, MWK

Manuscript Writing \& Approval:

UN, FS, MAS, MMA, MSZ, MWK

All the authors agree to be accountable for all aspects of the work in ensuring that questions related to the accuracy or integrity of any part of the work are appropriately investigated and resolved. 